\section{Identification of New (GT)n, (AC)n, (TC)n, and (TGA)n Microsatellite Alleles and their Effects on Teat Number in Sows}

\author{
Guofang Wu ${ }^{1,2}$, Xingxing Xue ${ }^{1}$, Wenjuan Shen ${ }^{1}$, Lei Wang ${ }^{1,2 *}$, Yuhong $\mathrm{Ma}^{1}$ and \\ Jiping Zhou ${ }^{1}$ \\ ${ }^{1}$ Academy of Animal Science and Veterinary Medicine, Qinghai University, Xining, \\ Qinghai 810016, China \\ ${ }^{2}$ State Key Laboratory of Plateau Ecology and Agriculture, Qinghai University, Xining, \\ Qinghai 810016, China
}

Guofang Wu and Xingxing Xue contributed equally to this work as co-first author.

\begin{abstract}
A B S T R A C T
Teat number is an important economic trait in the pig breeding industry and is directly related to the livability and growth status of piglets. By applying genetic technology, it may be possible to increase the number of teats and thus enhance production. Previous research has shown that teat number exhibits moderate levels of heritability that could be accelerated by the use of a genetic marker, such as microsatellites. Based on our preliminary sequencing data, the present study describes the use of timeof-flight mass spectrometry (TOF-MS) to identify the locations of four new microsatellites in Qinghai Bamei pig ( $\mathrm{n}=256)$, an indigenous breed of Chinese pig. TOF-MS demonstrated that the L1-(GT) locus had three alleles: 152 bp, 164 bp, and 166 bp. The three other loci, L2-(AC), L3-(TC), and L4-(TGA), all had two alleles. Alignment of our sequencing data with the Sus scrofa reference genome (Sscrofa11.1) revealed that the L1-(GT) microsatellite, which features a GT repeat motif, was located in the retinoic acid induced 2 gene (RAI2) on chromosome X in Sus scrofa (SSCX). Analysis further revealed that the $\mathrm{L} 2-(\mathrm{AC})$ locus, featuring $\mathrm{AC}$ repeats, and the $\mathrm{L} 3-(\mathrm{TC})$ locus, featuring TC repeats, were located in intergenic regions on SSC14 and SSC5, respectively. TGA repeats within the L4-(TGA) locus were located in the inner mitochondrial membrane peptidase subunit 2 gene (IMMPL2) on SSC18. Further association analysis revealed that the L1-(GT) locus was significantly associated with teat number $(p<$ 0.05 ) and that the 152-bp allele exhibited the most positive association. Our data indicate that the L1-(GT) n microsatellite could represent a potential DNA marker with which to increase the number of teats. Thus could help to improve production in the pig breeding industry.
\end{abstract}

Article Information
Received 26 March 2020
Revised 12 May 2020
Accepted 22 May 2020
Available online 27 March 2021
Authors' Contribution
LW designed the study. WS, YM and
JZ collected the samples and data.
GW and XX designed primers and
carried out the experiments. GW and
XX analyzed the data and wrote the
manuscript. GW and LW revised the
manuscript.
Key words
Simple sequence repeats (SSRs), Pig,
Teat number, Reproductive trait,
Time-of-flight mass spectrometry
(TOF-MS)

\section{INTRODUCTION}

$\mathrm{T}$ eat number is one of the most economically important traits in the pig industry (Patterson and Foxcroft, 2019; Zhou et al., 2019a). As breeding programs aim to increase litter size, it is important that they also aim to increase the number of teats in order to provide sufficient nutrition to all piglets. This is essential if we are to enhance the livability of piglets and their subsequent growth (Patterson and Foxcroft, 2019). Like most economically important traits, teat number is a complex quantitative trait that is likely to be controlled by one major gene working together with several minor genes (http://www.thepigsite. com/articles/5215/genetics-of-teat-number-in-swine/).

\footnotetext{
* Corresponding author: qhdxwanglei@126.com 0030-9923/2021/0003-1025 \$9.00/0

Copyright 2021 Zoological Society of Pakistan
}

Although it is difficult to achieve significant genetic progress in the short term when using traditional breeding methods (Dong et al., 2019), previous studies have shown that teat number in pigs is a moderately heritable trait, with heritability figures ranging from 0.2 to 0.4 (Chalkias et al., 2013; Felleki and Lundeheim, 2015; Earnhardt, 2019). Consequently, there is significant potential for breeders to apply molecular techniques to increase the number of teats (Ding et al., 2009; Rohrer and Nonneman, 2017). Several studies have reported that the Vertnin gene (VRTN), widely considered to be the gene responsible for thoracic vertebral number, can exert significant influence on teat number in pigs (Duijvesteijn et al., 2014; Yang et al., 2016; Rohrer and Nonneman, 2017; Tan et al., 2017). However, genome wide association studies (GWAS) have identified other significant polymorphic variations and genes that may play a potential role in the determination of teat number in pigs; however, the specific association between these molecular 
factors and teat number have yet to be elucidated (Zhou et al., 2019b).

Microsatellites are the main sources of polymorphic variation and are often referred to as short tandem repeats (STRs) or simple sequence repeats (SSRs) (Tian et al., 2011). These are DNA motifs consisting of $1-6$ nucleotides and are widely distributed within the genomes of prokaryotic and eukaryotic organisms (Tian et al., 2011). Throughout evolution, microsatellites exhibit a high mutation rate that ranges from $10^{3}$ to $10^{6}$ mutations per cell generation, far more than the frequency of point mutations (Gemayel et al., 2012). Due to their high degree of genetic variability, microsatellites often exhibit high levels of heterozygosity and multiple alleles (Ellegren, 2004). Because of these features, microsatellites are highly useful molecular markers for genetic diversity, markerassisted selection (MAS), linkage analysis, and forensics (Charoensook et al., 2019; Srivastava et al., 2019). Numerous studies have reported that some microsatellites show significant associations with traits that are beneficial to pig breeding (Cho et al., 2015; Wu et al., 2018; Xin et al., 2018). However, very few studies have explored the potential relationship between microsatellite markers and teat number in pigs (Hirooka et al., 2001; Sato et al., 2006; Zhang et al., 2007; Ding et al., 2009).

It is well established that indigenous pig breeds exhibit certain characteristics that are typical of commercial breeds. The Qinghai Bamei pig is a Chinese local pig breed that inhabits the Qinghai province, an area subject to a plateau continental climate (Zhang et al., 2018). In this particular ecological environment, and under the influence of both natural and artificial selection, Qinghai Bamei pigs exhibit a range of advantageous characteristics, including high resistance, excellent adaptability, good meat quality, a large litter size, and good maternal qualities (Zhang et al., 2018). However, this breed is also associated with some disadvantages, including slow growth, low fattening benefit, and low lactation performance (The editorial committee of Chinese livestock and poultry resources, 2004; Zhang et al., 2018). As with commercial pig breeds, Qinghai Bamei pigs have 6 to 7 pairs of teats. In contrast, the Taihu pig breed usually has 8 to 9 pairs of teats, although some individuals have been reported to have up to 18 pairs (The editorial committee of Chinese livestock and poultry resources, 2004). By applying genetic technology, it may be possible to increase the number of teats in Qinghai Bamei pigs and thus enhance their production. Increasing the number of teats would increase the supply of nutrients for piglets and improve the economic value of this breed with regard to commercial breeding. However, to our knowledge, no attempts have been made to identify potential molecular markers associated with teat number in the Qingai Bamei breed.

In a previous pilot sequencing data (unpublished), we found four new microsatellites in the genomes of Qinghai Bamei pigs. Therefore, in the present study, we identified these microsatellites and analyzed the association between these microsatellites and teat number in Qinghai Bamei pigs. We hoped to identify effective molecular markers with which to improve the production performance of these animals and to provide reference guidelines for the pig breeding industry.

\section{MATERIALS AND METHODS}

\section{Ethics}

All animal procedures, including sample collection and the measurement of specific traits, were carried out in accordance with relevant laws and institutional guidelines. In addition, our research was approved by the Institutional Animal Care and Use Committee of the Academy of Animal Science and Veterinary Medicine of Qinghai University (Approval number: NQH2019102).

\section{Samples and data collection}

A total of 256 adult female Qinghai Bamei pigs were randomly selected from the Qinghai Bamei Pig Original Breeding Farm, the Qinghai Huzhu Bamei Pig Breeding Farm, and the Qinghai Huangzhong County Breeding Farm. Ear samples were collected from each pig to allow for the extraction of genomic DNA. We also recorded the number of teats on each pig to analyze the genetic effects of the four target microsatellites.

\section{DNA extraction and primer design}

Samples of genomic DNA were extracted from ear tissue using the high-salt extraction method (Aljanabi and Martinez, 1997; Hui et al., 2020). The purity and quality of the extracted DNA samples were then determined using a Nanodrop 2000 Spectrometer (Thermo Scientific, Waltham, MA, USA). Then, the extracted DNAs were diluted to a working concentration of $20 \mathrm{ng} / \mu \mathrm{L}$ and stored at $-20^{\circ} \mathrm{C}$.

In a previous pilot study, we identified four new microsatellites in the genomes of Qinghai Bamei pigs by comparing transcriptome sequencing data and reducedrepresentation sequencing data (unpublished). This genomic sequence data showed only minor differences when compared with the Sus scrofa reference genome (Sscrofa11.1: GCF_000003025.6; National Center for Biotechnology Information (NCBI)). In the current study, we used genomic sequences from the Qinhaiu Bamei pig to design four specific pairs of primers to amplify the four target loci (Table I). 
Table I. The primers used for detection of microsatellites.

\begin{tabular}{|c|c|c|c|c|c|}
\hline $\begin{array}{l}\text { Primer } \\
\text { names }\end{array}$ & Primer sequences (5' - 3') & Sizes (bp) & $\begin{array}{l}\text { Repeat } \\
\text { motifs }\end{array}$ & Genes & Genome location \\
\hline \multirow[t]{2}{*}{$\mathrm{L} 1-(\mathrm{GT})_{\mathrm{n}}$} & F: CGGTCAATGCCAAAAGAAGT & \multirow[t]{2}{*}{152} & \multirow[t]{2}{*}{ GT } & \multirow[t]{2}{*}{ RAI2 } & \multirow{2}{*}{$\begin{array}{l}\text { ChrX:14403028-14403187 } \\
\text { (NC_010461.5) }\end{array}$} \\
\hline & R: GAGCTCAACCTGAGCACACA & & & & \\
\hline \multirow[t]{2}{*}{$\mathrm{L} 2-(\mathrm{AC})_{\mathrm{n}}$} & F: GTTGCTGTCAGCTGTGGTGT & \multirow[t]{2}{*}{192} & \multirow[t]{2}{*}{$\mathrm{AC}$} & \multirow{2}{*}{$\begin{array}{l}\text { intergenic } \\
\text { region }\end{array}$} & \multirow{2}{*}{$\begin{array}{l}\text { Chr14:29017381-29017572 } \\
\text { (NC_010456.5) }\end{array}$} \\
\hline & R: TGACCTTTTACTTTCTTTTCTTTCC & & & & \\
\hline \multirow[t]{2}{*}{ L3-(TC) } & F: GAGAGGATTCCTTCCCTTGG & \multirow[t]{2}{*}{111} & \multirow[t]{2}{*}{$\mathrm{TC}$} & \multirow{2}{*}{$\begin{array}{l}\text { intergenic } \\
\text { region }\end{array}$} & \multirow{2}{*}{$\begin{array}{l}\text { Chr5:31862546-31862656 } \\
\text { (NC_010447.5) }\end{array}$} \\
\hline & R: GTAGCGAATGGCCAAGTCAT & & & & \\
\hline \multirow[t]{2}{*}{ L4-(TGA) } & F: GTTGTCATTTGTGTGCCTGC & \multirow[t]{2}{*}{115} & \multirow[t]{2}{*}{ TGA } & \multirow[t]{2}{*}{ IMMP2L } & \multirow{2}{*}{$\begin{array}{l}\text { Chr18:34033513-34033627 } \\
\text { (NC_010460.4) }\end{array}$} \\
\hline & R: AAAAAGGTTGGAACACTCAAAG & & & & \\
\hline
\end{tabular}

$R A I 2$, retinoic acid induced 2; IMMP2L, inner mitochondrial membrane peptidase subunit 2 . The location of all amplified fragments and microsatellites were aligned with Sus scrofa reference genome (Sscrofa11.1).

Table II. Genotypic and allelic frequencies and genetic diversity of four microsatellites in Qinghai Bamei pig population.

\begin{tabular}{|c|c|c|c|c|c|c|c|c|c|c|}
\hline \multirow{2}{*}{$\begin{array}{l}\text { Loci } \\
\text { L1-(GT)n }\end{array}$} & \multirow{2}{*}{$\begin{array}{l}\text { Sample size } \\
\mathrm{n}=238\end{array}$} & \multicolumn{2}{|c|}{ Genotypic frequencies } & \multicolumn{2}{|c|}{ Allelic frequencies } & \multirow{2}{*}{$\begin{array}{l}\text { Ho } \\
0.419\end{array}$} & \multirow{2}{*}{$\begin{array}{l}\mathbf{H e} \\
0.581\end{array}$} & \multirow{2}{*}{$\frac{\mathrm{Ne}}{2.385}$} & \multirow{2}{*}{$\begin{array}{l}\text { PIC } \\
0.489\end{array}$} & \multirow{2}{*}{$\begin{array}{l}\text { HWE } \\
\chi^{2}=9.070\end{array}$} \\
\hline & & $152-/ 152-$ & 0.210 & $152-$ & 0.456 & & & & & \\
\hline & & $152-/ 164-$ & 0.109 & $164-$ & 0.094 & & & & & $p=0.003$ \\
\hline & & $152-/ 166-$ & 0.383 & $166-$ & 0.450 & & & & & \\
\hline & & $164-/ 164-$ & 0.017 & & & & & & & \\
\hline & & $164-/ 166-$ & 0.046 & & & & & & & \\
\hline & & $166-/ 166-$ & 0.235 & & & & & & & \\
\hline \multirow[t]{3}{*}{$\mathrm{L} 2-(\mathrm{AC})_{\mathrm{n}}$} & $\mathrm{n}=249$ & 190-/190- & 0.558 & $190-$ & 0.745 & 0.620 & 0.380 & 1.613 & 0.308 & $\chi^{2}=0.072$ \\
\hline & & $190-/ 192-$ & 0.374 & $192-$ & 0.255 & & & & & $p=0.788$ \\
\hline & & 192-/192- & 0.068 & & & & & & & \\
\hline \multirow[t]{2}{*}{ L3-(TC) $)_{n}$} & $\mathrm{n}=254$ & $105-/ 109-$ & 0.114 & $105-$ & 0.057 & 0.892 & 0.108 & 1.120 & 0.102 & $\chi 2=0.013$ \\
\hline & & 109-/109- & 0.886 & $109-$ & 0.943 & & & & & $p=0.748$ \\
\hline \multirow[t]{3}{*}{ L4-(TGA) } & $\mathrm{n}=256$ & $110-/ 110-$ & 0.180 & $110-$ & 0.232 & 0.644 & 0.356 & 1.554 & 0.293 & $\chi 2=127.024$ \\
\hline & & $110-/ 113-$ & 0.105 & $113-$ & 0.768 & & & & & $p=1.84 \times 10^{-29}$ \\
\hline & & 113-/113- & 0.715 & & & & & & & \\
\hline
\end{tabular}

$\mathrm{Ho}$, homozygosity; $\mathrm{He}$, heterozygosity; $\mathrm{Ne}$, effective allele numbers; PIC, polymorphism information content; HWE, Hardy-Weinberg equilibrium.

PCR amplification and the genotyping of microsatellites by time-of-flight mass spectrometry (TOF-MS)

The procedure for microsatellites genotyping mainly contained three steps: PCR amplification, MS detection, and results analysis, which were conducted by the company (Saisike Biotechnology Co., Ltd., Xining, Qinghai, China). The detailed procedure simply described as follows. First, genomic DNA was amplified from each pig using specific primers (Table I). Second, each PCR product was dropped to a SpectroCHIP Array and detected by MassARRAY ${ }^{\circledR}$ System (Agena Bioscience, San Diego, USA) according to the manufacturer's instructions. The different mass of DNA fragments determined the relative time of flight (Ragoussis et al., 2006). Finally, according to the arrival time of DNA fragments, the system drew a mass spectrum that displayed different genotyping.

\section{Statistical analysis}

Genotypic and allelic frequencies, along with the Hardy-Weinberg equilibrium (HWE), were calculated using standard methodology (Wang et al., 2020a). Population indexes, including polymorphism information content (PIC), homozygosity $(\mathrm{Ho})$, heterozygosity $(\mathrm{He})$, and effective allele numbers $(\mathrm{Ne})$, were calculated as described previously by Liu et al. (1998).

Analysis of variance (ANOVA), a general linear 
model, was used to analyze the relationship between different genotypes and teat number and was carried out with SPSS 26.0 statistical software package (IBM, New York, NY, USA). The statistical model was $\mathrm{Y}_{\mathrm{ij}}=\mu+\mathrm{G}_{\mathrm{i}}+$ $\varepsilon_{\mathrm{ij}}$, in which $\mathrm{Y}_{\mathrm{ij}}$ represents the teat number, $\mu$ represents the population mean, $\mathrm{G}_{\mathrm{i}}$ represents the fixed effect of genotype, and $\varepsilon_{\mathrm{ij}}$ represents random error (Lan et al., 2007). The model excluded the effects of farm, age, and sire, which have been proven to have no significant effects $(p>0.05)$ on the variation of the traits examined in this population (Lan et al., 2007). The student's t-test was used for twogroup comparisons and ANOVA was used for multi-group comparisons following correction by Tukey's multiple test (Wang et al., 2019, 2020b). All data are presented as the mean \pm standard error of the mean (S.E.M.), and $p<0.05$ was considered to be statistically significant.

\section{RESULTS}

The identification of microsatellite polymorphisms in Qinghai Bamei pigs

In our previous study, we identified four new microsatellites in the genomes of Qinghai Bamei pigs. Using this data, we designed specific primers (Table I) to amplify fragments of genomic DNA that included these loci. We then sequenced the PCR amplicons and analyzed them by TOF-MS. The TOF-MS data demonstrated that the four microsatellites were present in several different genotypes (Figs. 1-4). The L1-(GT) locus possessed GT repeat variations and was observed in six genotypes in our study population: 152-/152-, 152-/164-, 152-/166-, 164/164-, 164-/166-, and 166-/166-bp (Fig. 1). Alignment with the Sus scrofa genome (Sscrofa11.1) revealed that the (GT) microsatellite was located in the retinoic acid induced 2 gene (RAI2) on chromosome X in Sus scrofa (SSCX) (Table I). The L2-(AC) locus featured a repeat AC motif and was associated with three genotypes: 190-/190-, 190-/192-, and 192-/192-bp (Fig. 2). This microsatellite was located in the intergenic region of SSC14, which lies between the uncharacterized LOC110256597 gene and the zinc finger protein 664 gene (ZNF664) (Table I). Only two variants of the L3-(TC) locus (105-/109- and 109-/109-bp) were detected (Fig. 3); this (TC) microsatellite polymorphism was located in the intergenic region between the cullinassociated and neddylation-dissociated 1 gene (CAND1) and the dual specificity tyrosine phosphorylation regulated kinase 2 gene (DYRK2) on SSC5 (Table I). Finally, the L4-(TGA) locus was associated with three different genotypes: 110-/110-, 110-/113-, and 113-/113-bp (Fig. 4). This microsatellite was located in the inner mitochondrial membrane peptidase subunit 2 gene (IMMPL2) on SSC18 (Table I).

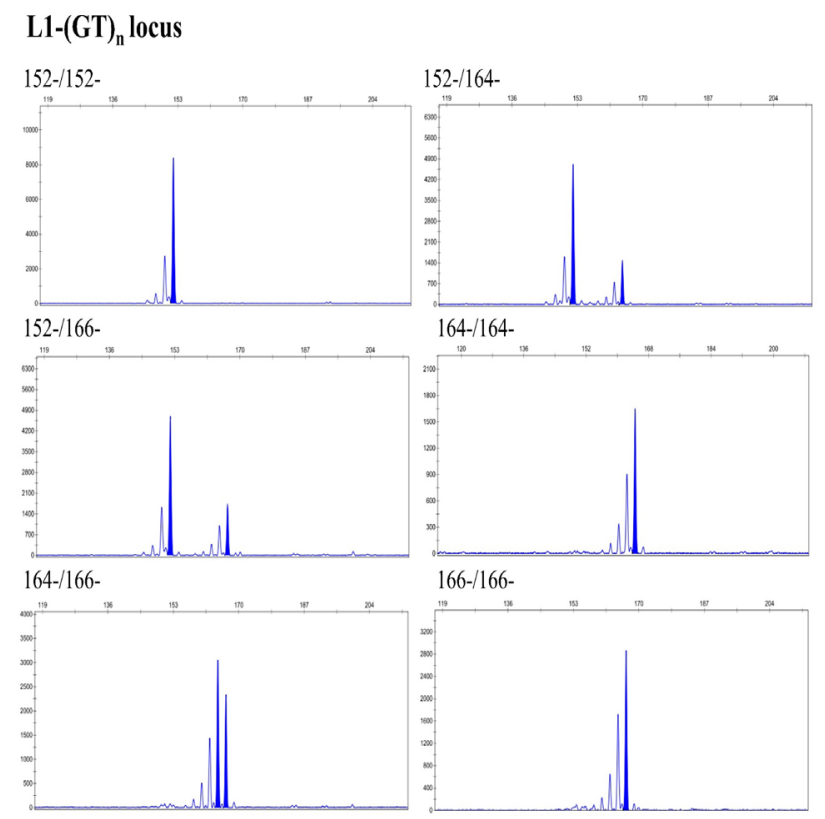

Fig. 1. Genotyping of the L1-(GT) $)_{n}$ locus in pigs using TOF-MS.

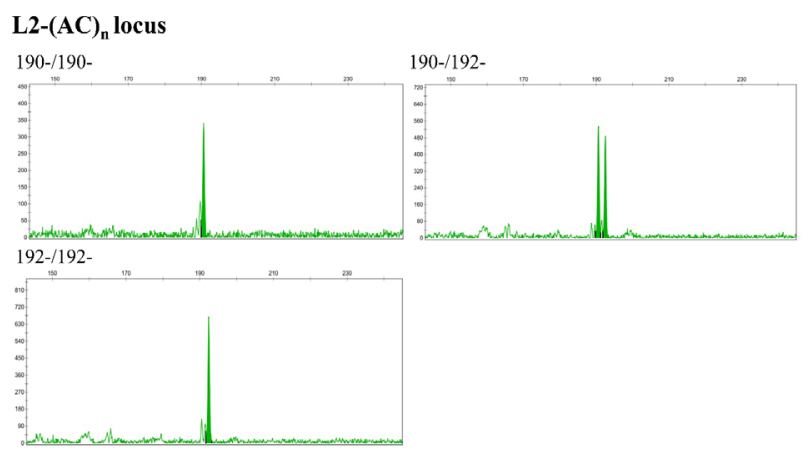

Fig. 2. Genotyping of the L2-(AC) locus in pigs using TOF-MS.

Genotypic and allelic frequencies and the genetic diversity of microsatellites in Qinghai Bamei pigs

The genotypic and allelic frequencies of the four microsatellites in Qinghai Bamei pigs are shown in Table II; the minimum allele frequencies (MAF) were 0.094, 0.255, 0.057 and 0.232 for the L1-(GT), L2-(AC), L3-(TC), and L4-(TGA) loci, respectively. Next, we calculated a range of population indices ( $\mathrm{Ho}, \mathrm{He}, \mathrm{Ne}$, and PIC) to evaluate the genetic diversity of the four microsatellites (Table II). When compared with other loci, individuals with the L1(GT) locus showed the highest levels of heterozygosity; there were six genotypes created by the three alleles at this particular locus. With the exception of the L3-(TC) locus, the other three loci all show moderate levels of genetic 
diversity $(0.25<\mathrm{PIC}<0.5)$. Furthermore, chi-squared analysis demonstrated that only the L2-(AC) and L3-(TC) ${ }_{n}$ loci were in accordance with HWE ( $p>0.05$; Table II).

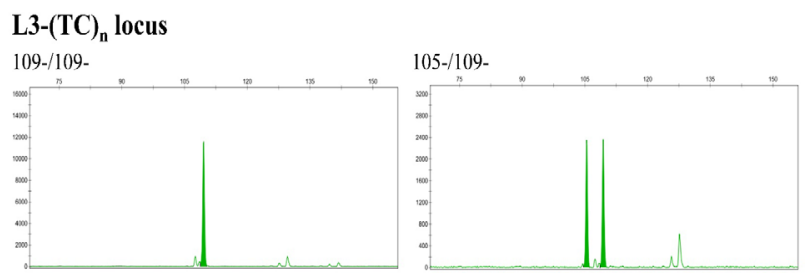

Fig. 3. Genotyping of the L3-(TC) locus in pigs using TOF-MS.

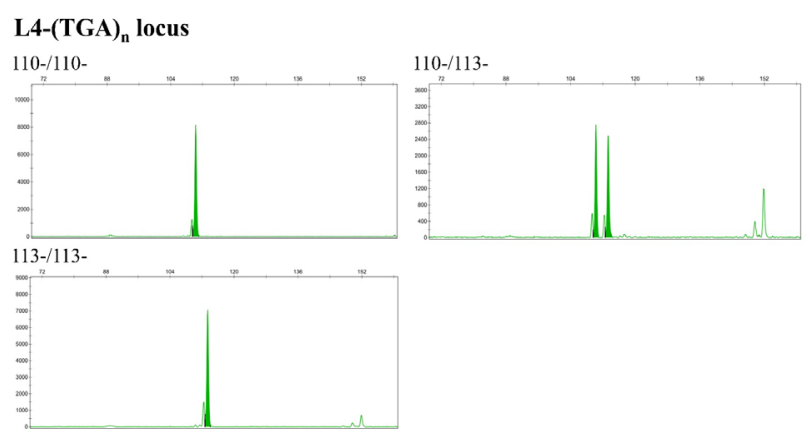

Fig. 4. Genotyping of the L4-(TGA) locus in pigs using TOF-MS.

\section{Association analysis of the four microsatellites with teat} number in Qinghai Bamei pigs

Association analysis demonstrated that the L1-(GT) n locus was significantly associated with teat number $(p<$ 0.05; Table III). Pigs possessing the 152-/152-, 152-/164-, and 152-/166-bp genotypes at the L1-(GT) locus all had a greater number of teats than those with any of the other genotypes $(p<0.05)$. Pigs with the 164-/164-bp genotype had the lowest number of teats $(p<0.05)$. However, none of the other three microsatellites had any significant association with teat number $(p>0.05$; Table III).

\section{DISCUSSION}

Teat number is an important economic trait in the pig breeding industry and is directly related to the livability and growth status of piglets. By applying genetic technology, it may be possible to increase the number of teats and thus enhance production (Patterson and Foxcroft, 2019; Zhou et al., 2019). Research has shown that teat number is a trait with moderate levels of heritability. As such, selection could be expedited by the application of genetic makers, such as SNPs, indels, and microsatellites (Felleki and Lundeheim, 2015; Earnhardt, 2019). However, thus far, only a very limited number of candidate quantitative trait loci (QTLs) and genes have been identified that show some form of association with teat number in pigs, although the VRTN gene appears to be promising (Duijvesteijn et al., 2014; Yang et al., 2016; Rohrer and Nonneman, 2017; Tan et al., 2017; Zhou et al., 2019). However, as this type of quantitative trait cannot be controlled effectively by a limited number of genes or loci, it is vital that we identify a wider range of functional genetic markers. In the current study, we selected an indigenous breed of Chinese pig (Qinghai Bamei) and investigated the association between specific microsatellites and teat number. In our previous research, we identified four new microsatellites in Qinghai Bamei pigs. In the present study, we used TOF-MS to genotype these microsatellites in a large population of pigs. TOF-MS has developed rapidly over recent years, largely due to its high levels of sensitivity and accuracy, and because it provides a rapid and automated approach to screening (van den et al., 2001; Mann, 2019). The combination of conventional PCR amplification and TOF-MS is a far more suitable method for analyzing microsatellites than next generation sequencing because continuous repeat sequences may confuse the recognition and assembly of sequence fragments in the latter technique. Using TOF-MS, we found that the four microsatellites exhibited multiple alleles in Qinghai Bamei pigs. The L1(GT) locus possessed a GT repeat motif and had three alleles (152-, 164-, and 166-bp) and six genotypes (Fig. 1); the other three loci only had two alleles (Figs. 2-4). The frequencies of the 152- and 166-bp alleles at the L1-(GT) locus were both $>0.45$; however, the frequency of the 164-bp allele was only 0.094 (Table II). The major alleles of the other three microsatellites were 190-, 109-, and 113$\mathrm{bp}$, respectively; the frequency exceeded 0.70 in each case (Table II)). The genetic distribution and frequency data demonstrated that the $(\mathrm{GT})_{\mathrm{n}}$ repeat sequences have greater levels of genetic diversity and that the 164-bp allele may be gradually eliminated in Qinghai Bamei pigs during both natural and artificial selection.

Alignment of our sequencing data with the Sus scrofa reference genome (Sscrofa11.1), showed that these new microsatellites were scattered across different chromosomes. The L1-(GT) microsatellites were located in the RAI2 gene on SSCX (Table I). More specifically, the $(\mathrm{GT})_{\mathrm{n}}$ repeat element was located in intron 1 of the RAI2 isoform X1 (mRNA accession numbers: XM_021080586.1, XM_021080587.1, XM_021080588.1, XM_021080589.1; protein accession numbers: XP_020936245.1, XP_020936246.1, XP_020936247.1, XP_020936248.1) or were located in the 5' untranslated region (UTR) of the X1 (XM_021080590.1; XP_020936249.1) and X3 (XM_021080591.1, 
XM_021080592.1, XM_021080594.1, XM_021080595.1, XM_013985950.2; XP_020936250.1, XP_020936251.1, XP_020936253.1, XP_020936254.1) isoforms of RAI2. The L2-(AC) microsatellites were intergenic and located downstream of the refilin A gene (NC_010456.5) and the LOC110256597 gene, and upstream of the ZNF664 gene, on SSC14 (Table I). The other dinucleotide microsatellite, L3-(TC) ${ }_{n}$, possessed a TC repeat sequence and was located between the CAND1 gene and the DYRK2 gene on SSC5

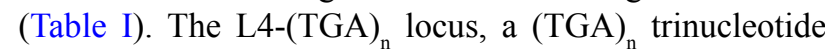
microsatellite, was located in the 5'-UTR of the IMMP2L gene of all four isoforms on SSC18 (Table I). Since these microsatellites were distributed in non-coding regions, it is possible that they may result in changes to the elements responsible for the initiation of transcription and translation, particularly if located in the 5'-UTR; they may also affect mRNA splicing or cause export to the cytoplasm if located in intronic regions (Li et al., 2004). Furthermore, it is possible that these variants could be linked with other QTLs and thus exert an indirect effect on gene expression and phenotypes (Zhang et al., 2019).

Next, we investigated whether these new microsatellites were associated with teat number. Our analysis indicated that only the L1-(GT) $)_{\mathrm{n}}$ microsatellite had a significant association with teat number $(p<0.05$; Table III). Further analysis showed that the 152-/152-, 152-/164-, and 152-/166-bp genotypes were superior and that the 152-bp allele was a superior allele. Data further indicated that shorter GT repeats were associated with a greater number of teats. Considering the specific genomic locations of this variant, which was located in either the 5'-UTR or intron 1 of the RAI2 gene, we hypothesize that a change in the number of repeats might play a role in the post-transcriptional processing of RAI2, particularly in terms of mRNA splicing. We presume that $(\mathrm{GT})_{\mathrm{n}}$ repeats may participate in this process as a recognized element of the spliceosome (Wahl et al., 2009), because the only difference is the first exon skipping or not when pre-mRNA was processed to mature mRNA. The RAI2 gene encodes retinoic acid-induced 2 protein, a protein that is considered to play a key role in development (Jonk et al., 1994). By participating in the retinoic acid signaling pathway, the RAI2 protein also plays key roles in cellular growth and cell differentiation (Cañete et al., 2017), and is expressed widely in various mammalian tissues (Liao et al., 2011). The RAI2 protein has also been linked with a number of human diseases, including Nance-Horan syndrome (Liao et al., 2011). Recent studies have reported that RAI2 acts as a novel oncogenic factor in colorectal cancer (Yan et al., 2018), breast cancer (Werner et al., 2015; Katharina et al., 2018), and prostate cancer (Hoffmann et al., 2017). As yet, there are no publications indicating that RAI2 plays a direct role in the determination of teat number or other related physiological processes, such as thoracic vertebral development. Future studies are now needed to address these unanswered questions.

Table III. Association of four microsatellites with teat number of pigs.

\begin{tabular}{lllll}
\hline Loci & Genotypes & Numbers & Mean \pm S.E. & p Values \\
\hline L1-(GT) & $152-/ 152-$ & 46 & $12.78^{\mathrm{a}} \pm 0.18$ & $p=0.044$ \\
& $152-/ 164-$ & 25 & $13.04^{\mathrm{a}} \pm 0.33$ & \\
& $152-/ 166-$ & 63 & $12.60^{\mathrm{a}} \pm 0.17$ & \\
& $164-/ 164-$ & 4 & $11.25^{\mathrm{b}} \pm 0.48$ & \\
& $164-/ 166-$ & 6 & $12.17^{\mathrm{ab}} \pm 0.54$ & \\
& $166-/ 166-$ & 34 & $12.26^{\mathrm{ab}} \pm 0.20$ & \\
L2-(AC) & $190-/ 190-$ & 75 & $12.51 \pm 0.15$ & $p=0.589$ \\
& $190-/ 192-$ & 50 & $12.72 \pm 0.17$ & \\
& $192-/ 192-$ & 14 & $12.79 \pm 0.45$ & \\
L3-(TC) & $105-/ 109-$ & 22 & $12.73 \pm 0.31$ & $p=0.727$ \\
& $109-/ 109-$ & 121 & $12.62 \pm 0.12$ & \\
L4-(TGA) & $110-/ 110-$ & 29 & $12.31 \pm 0.22$ & $p=0.248$ \\
& $110-/ 113-$ & 13 & $13.00 \pm 0.47$ & \\
& $113-/ 113-$ & 101 & $12.66 \pm 0.13$ & \\
\hline
\end{tabular}

Values with different letters $(\mathrm{a}, \mathrm{b})$ differ significantly at $p<0.05$.

Previous research has also reported that several QTLs on chromosome (SSC) X in Sus scrofa are related to teat number in pigs (Cepica et al., 2003); the area mapped to these QTLs $(0-35.2 \mathrm{cM})$ also include the L1-(GT) locus (please refer to the QTL map featured in the Pig Quantitative Trait Locus Database (Pig QTLdb) (Hu et al., 2019). In addition, by reference to the Pig QTLdb, we also identified other QTLs that were related to teat number on the same chromosome, including an SNP (rs336814005) within the thymosin beta $4 \mathrm{X}$-linked gene (TMSB4X) gene (Zhou et al., 2019), and several SNPs with a more dominant effect (ALGA0098952, H3GA0051701, MARC0069431, H3GA0051890, ALGA0099918, MARC0068856) (Rohrer and Nonneman, 2017). These loci, including the L1-(GT) locus, might be linked with each other, or with other QTLs on other chromosomes, such as QTLs in the VRTN gene, in order to exert indirect effects on gene expression.

Although the three other microsatellites (L2-(AC) n, L3-(TC) , and L4-(TGA) ) had no significant effects on teat number in Qinghai Bamei pigs, it is possible that they might affect key production traits. According to the Pig QTLdb database, the L2-(AC) locus on SSC14 is located close to some QTLs that are known to be associated with average daily gain, daily feed intake 
(Onteru et al., 2013), litter size (He et al., 2017), and obesity index (Kogelman et al., 2014). The L3-(TC) microsatellites on SSC5 are also located in close proximity to sites related to the ear area (Zhang et al., 2014). With regard to the L4-(TGA) locus, we found that the repeat motif (TGA) was located in the 5'-UTR of the IMMPL2 gene, a gene that is known to be involved in processing the transmembrane of proteins from the inner mitochondrial membrane to the inter-membrane space. Mutations in the IMMPL2 gene have been identified in patients with Tourette's syndrome (Petek et al., 2007). In addition, this mitochondrial protease has been shown to suppress cellular senescence (Yuan et al., 2018). Furthermore, analysis of the Pig QTLdb has shown that loci located in close proximity of L4-(TGA) can influence a number of key traits, including age at puberty (Nonneman et al., 2014), blood pH (Reiner et al., 2009), palmitic acid content (Ramayo-Caldas et al., 2012), and several growth-related traits (Liu et al., 2008; Wei et al., 2011). Considering the function of the IMMPL2 gene, and its proximity to QTLs, we hypothesize that the L4-(TGA) locus might exert unknown effects that need to be investigated further.

\section{CONCLUSIONS}

In this study, we used TOF-MS to identify the locations of four novel microsatellites in the genomes of Qinghai Bamei pigs: L1-(GT), L2-(AC), L3-(TC), and L4-(TGA)n. The L1-(GT) locus was located in the RAI2 gene, L2-(AC) $)_{\mathrm{n}}$ and L3-(TC) $)_{\mathrm{n}}$ were located in intergenic regions, and L4-(TGA) $)_{n}$ was located in the IMMPL2 gene. The L1-(GT)n locus was associated with six genotypes and three alleles, while the other loci were only associated with two alleles. Further association analysis revealed that the L1-(GT) locus was significantly associated with teat number and that the 152-bp allele was the beneficial allele. This association suggests that the L1-(GT) microsatellite could represent a potential DNA marker with which to improve teat number in pigs and could be beneficial to pig breeding programs.

\section{ACKNOWLEDGMENTS}

This research was funded by Achievement Transformation Project of Science and Technology of Qinghai Province (Grant No. 2019-NK-102). In addition, we would like to thank Qinghai Bamei Pig Original Breeding Farm, the Qinghai Huzhu Bamei Pig Breeding Farm and the Qinghai Huangzhong County Breeding Farm for samples and data collection.
Statement of conflict of interest

The authors have declared no conflict of interest.

\section{REFERENCES}

Aljanabi, S.M. and Martinez, I., 1997. Universal and rapid salt-extraction of high quality genomic DNA for PCR-based techniques. Nucl. Acids Res., 25: 4692-4693. https://doi.org/10.1093/nar/25.22.4692

Cañete, A., Cano, E., Muñoz-Chápuli, R. and Carmona, R., 2017. Role of vitamin A/retinoic acid in regulation of embryonic and adult hematopoiesis. Nutrients, 9: E159. https://doi.org/10.3390/ nu9020159

Cepica, S., Reiner, G., Bartenschlager, H., Moser, G. and Geldermann, H., 2003. Linkage and QTL mapping for Sus scrofa chromosome X. J. Anim. Breed Genet., 120: 144-151. https://doi.org/10.1046/ j.0931-2668.2003.00436.x

Chalkias, H., Rydhmer, L. and Lundeheim, N., 2013. Genetic analysis of functional and non-functional teats in a population of Yorkshire pigs. Livest. Sci., 152: 127-134. https://doi.org/10.1016/j. livsci.2013.01.003

Charoensook, R., Gatphayak, K., Brenig, B. and Knorr, C., 2019. Genetic diversity analysis of Thai indigenous pig population using microsatellite markers. Asian-Australas. J. Anim. Sci., 32: 14911500. https://doi.org/10.5713/ajas.18.0832

Cho, I.C., Yoo, C.K., Lee, J.B., Jung, E.J., Han, S.H., Lee, S.S., Ko, M.S., Lim, H.T. and Park, H.B., 2015. Genome-wide QTL analysis of meat quality-related traits in a large F2 intercross between Landrace and Korean native pigs. Genet. Sel. Evol., 47: 7. https:// doi.org/10.1186/s12711-014-0080-6

Ding, N., Guo, Y., Knorr, C., Ma, J., Mao, H., Lan, L., Xiao, S., Ai, H., Haley, C.S., Brenig, B. and Huang, L., 2009. Genome-wide QTL mapping for three traits related to teat number in a White Duroc $\mathrm{x}$ Erhualian pig resource population. BMC Genet., 10: 6. https://doi.org/10.1186/1471-2156-10-6

Dong, C., Zhang, X., Liu, K., Li, B., Chao, Z., Jiang, A., Li, R., Li, P., Liu, H. and Wu, W., 2019. Comprehensive analysis of porcine Prox 1 gene and its relationship with meat quality traits. Animals (Basel), 9: pii: E744. https://doi.org/10.3390/ ani9100744

Duijvesteijn, N., Veltmaat, J.M., Knol, E.F. and Harlizius, B., 2014. High-resolution association mapping of number of teats in pigs reveals regions controlling vertebral development. BMC Genom., 15: 542. https://doi.org/10.1186/1471-2164-15-542 
Earnhardt, A., 2019. The genetics of functional teats in swine. M.S. thesis, North Carolina State University, Raleigh, USA.

Ellegren, H., 2004. Microsatellites: Simple sequences with complex evolution. Nat. Rev. Genet., 5: 435445. https://doi.org/10.1038/nrg1348

Felleki, M. and Lundeheim, N., 2015. Genetic heteroscedasticity of teat count in pigs. $J$. Anim. Breed Genet., 132: 392-398. https://doi. org/10.1111/jbg.12134

Gemayel, R., Cho, J., Boeynaems, S. and Verstrepen, K.J., 2012. Beyond junk-variable tandem repeats as facilitators of rapid evolution of regulatory and coding sequences. Genes (Basel), 3: 461-480. https://doi.org/10.3390/genes3030461

Genetics of teat number in swine, 2016. Partners Available at: http://www.thepigsite.com/ articles/5215/genetics-of-teat-number-in-swine/ (accessed 28 Feb 2020).

He, L.C., Li, P.H., Ma, X., Sui, S.P., Gao, S., Kim, S.W., Gu, Y.Q., Huang, Y., Ding, N.S. and Huang, R.H., 2017. Identification of new single nucleotide polymorphisms affecting total number born and candidate genes related to ovulation rate in Chinese Erhualian pigs. Anim. Genet., 48: 48-54. https:// doi.org/10.1111/age.12492

Hirooka, H., de Koning, D.J., Harlizius, B., van Arendonk, J.A., Rattink, A.P., Groenen, M.A., Brascamp, E.W. and Bovenhuis, H., 2001. A wholegenome scan for quantitative trait loci affecting teat number in pigs. J. Anim. Sci., 79: 2320-2326. https://doi.org/10.2527/2001.7992320x

Hoffmann, T.J., Passarelli, M.N., Graff, R.E., Emami, N.C., Sakoda, L.C., Jorgenson, E., Habel, L.A., Shan, J., Ranatunga, D.K., Quesenberry, C.P., Chao, C.R., Ghai, N.R., Aaronson, D., Presti, J., Nordström, T., Wang, Z., Berndt, S.I., Chanock, S.J., Mosley, J.D., Klein, R.J., Middha, M., Lilja, H., Melander, O., Kvale, M.N., Kwok, P.Y., Schaefer, C., Risch, N., Van Den Eeden, S.K. and Witte, J.S., 2017. Genome-wide association study of prostate-specific antigen levels identifies novel loci independent of prostate cancer. Nat. Commun., 8: 14248 . https://doi.org/10.1038/ncomms 14248

Hu, Z.L., Park, C.A. and Reecy, J.M., 2019. Building a livestock genetic and genomic information knowledgebase through integrative developments of animal QTLdb and CorrDB. Nucl. Acids Res., 47: D701-D710. https://doi.org/10.1093/nar/ gky1084

Hui, Y., Zhang, Y., Wang, K., Pan, C., Chen, H., Qu, L., Song, X. and Lan, X., 2020. Goat DNMT3B:
An indel mutation detection association analysis with litter size and mRNA expression in gonads. Theriogenology, 147: 108-115. https://doi. org/10.1016/j.theriogenology.2020.02.025

Jonk, L.J., de Jonge, M.E., Vervaart, J.M., Wissink, S. and Kruijer, W. 1994. Isolation and developmental expression of retinoic-acid-induced genes. Dev. Biol., 161: 604-614. https://doi.org/10.1006/ dbio.1994.1056

Katharina, Besler., Aleksandra, Weglarz., Christina, Zill., Jana, Jensen., Harriet, Wikman., Klaus, Pantel. and Stefan, Werner., 2018. Role of RAI2 protein in progression of breast and prostate cancer to hormone independent disease. AACR Annual Meeting 2018 USA APR 14-18; American Association for Cancer Research: Philadelphia PAUSA 2018; Abstract Number: 3736. https://doi. org/10.1158/1538-7445.AM2018-3736

Kogelman, L.J., Pant, S.D., Fredholm, M. and Kadarmideen, H.N., 2014. Systems genetics of obesity in an F2 pig model by genome-wide association genetic network and pathway analyses. Front. Genet., 5: 214. https://doi.org/10.3389/ fgene.2014.00214

Lan, X.Y., Pan, C.Y., Chen, H., Zhang, C.L., Li, J.Y., Zhao, M., Lei, C.Z., Zhang, A.L. and Zhang, L., 2007. An AluI PCR-RFLP detecting a silent allele at the goat POU1F1 locus and its association with production traits. Small Rumin. Res., 73: 8-12. https://doi.org/10.1016/j.smallrumres.2006.10.009

Li, Y.C., Korol, A.B., Fahima, T. and Nevo, E., 2004. Microsatellites within genes: Structure function and evolution. Mol. Biol. Evol., 21: 991-1007. https://doi.org/10.1093/molbev/msh073

Liao, H.M., Niu, D.M., Chen, Y.J., Fang, J.S., Chen, S.J. and Chen, C.H., 2011. Identification of a microdeletion at Xp22.13 in a Taiwanese family presenting with Nance-Horan syndrome. $J$. Hum. Genet., 56: 8-11. https://doi.org/10.1038/ jhg.2010.121

Liu, B.H., 1998. Statistical genomics: Linkage mapping and QTL analysis. 1st edn. CRC Press, USA.

Liu, G., Kim, J.J., Jonas, E., Wimmers, K., Ponsuksili, S., Murani, E., Phatsara, C., Tholen, E., Juengst, H., Tesfaye, D., Chen, JL. and Schellander, K., 2008. Combined line-cross and half-sib QTL analysis in Duroc-Pietrain population. Mammal. Genome, 19: 429-438. https://doi.org/10.1007/s00335-0089132-y

Mann, M., 2019. The ever expanding scope of electrospray mass spectrometry-a 30 year journey. Nat. Commun., 10: 3744. https://doi.org/10.1038/ 
s41467-019-11747-z

Nonneman, D., Lents, C., Rohrer, G., Rempel, L. and Vallet, J., 2014. Genome-wide association with delayed puberty in swine. Anim. Genet., 45: 130132. https://doi.org/10.1111/age.12087

Onteru, S.K., Gorbach, D.M., Young, J.M., Garrick, D.J., Dekkers, J.C. and Rothschild, M.F., 2013. Whole genome association studies of residual feed intake and related traits in the pig. PLoS One, 8: e61756. https://doi.org/10.1371/journal.pone.0061756

Patterson, J. and Foxcroft, G., 2019. Gilt management for fertility and longevity. Animals (Basel), 9: pii:E434. https://doi.org/10.3390/ani9070434

Petek, E., Schwarzbraun, T., Noor, A., Patel, M., Nakabayashi, K., Choufani, S., Windpassinger, C., Stamenkovic, M., Robertson, M.M., Aschauer, H.N., Gurling, H.M., Kroisel, P.M., Wagner, K., Scherer, S.W. and Vincent, J.B., 2007. Molecular and genomic studies of IMMP2L and mutation screening in autism and Tourette syndrome. Mol. Genet. Genom., 277: 71-81. https://doi. org/10.1007/s00438-006-0173-1

Ragoussis, J., Elvidge, G.P., Kaur, K. and Colella, S., 2006. Matrix-assisted laser desorption/ionisation time-of-flight mass spectrometry in genomics research. PLoS Genet., 2: e100. https://doi. org/10.1371/journal.pgen.0020100

Ramayo-Caldas, Y., Mercadé, A., Castelló, A., Yang, B., Rodríguez, C., Alves, E., Díaz, I., IbáñezEscriche, N., Noguera, J.L., Pérez-Enciso, M., Fernández, A.I. and Folch, J.M., 2012. Genomewide association study for intramuscular fatty acid composition in an Iberian $\times$ Landrace cross. $J$. Anim. Sci., 90: 2883-2893. https://doi.org/10.2527/ jas.2011-4900

Reiner, G., Fischer, R., Köhler, F., Berge, T., Hepp, S. and Willems, H., 2009. Heritabilities and quantitative trait loci for blood gases and blood $\mathrm{pH}$ in swine. Anim. Genet., 40: 142-148. https://doi. org/10.1111/j.1365-2052.2008.01813.x

Rohrer, G.A. and Nonneman, D.J., 2017. Genetic analysis of teat number in pigs reveals some developmental pathways independent of vertebra number and several loci which only affect a specific side. Genet. Sel. Evol., 49: 4. https://doi. org/10.1186/s12711-016-0282-1

Sato, S., Atsuji, K., Saito, N., Okitsu, M., Sato, S., Komatsuda, A., Mitsuhashi, T., Nirasawa, K., Hayashi, T., Sugimoto, Y. and Kobayashi, E., 2006. Identification of quantitative trait loci affecting corpora lutea and number of teats in a Meishan $\mathrm{x}$ Duroc F2 resource population. J. Anim. Sci., 84:
2895-2901. https://doi.org/10.2527/jas.2006-176

Srivastava, S., Avvaru, A.K., Sowpati, D.T. and Mishra, R.K., 2019. Patterns of microsatellite distribution across eukaryotic genomes. BMC Genom., 20: 153. https://doi.org/10.1186/s12864-019-5516-5

Tan, C., Wu, Z., Ren, J., Huang, Z., Liu, D., He, X., Prakapenka, D., Zhang, R., Li, N., Da, Y. and Hu, $\mathrm{X}$., 2017. Genome-wide association study and accuracy of genomic prediction for teat number in Duroc pigs using genotyping-by-sequencing. Genet. Sel. Evol., 49: 35. https://doi.org/10.1186/ s12711-017-0311-8

Tian, X., Strassmann, J.E. and Queller, D.C., 2011. Genome nucleotide composition shapes variation in simple sequence repeats. Mol. Biol. Evol., 28: 899-909. https://doi.org/10.1093/molbev/msq266

The editorial committee of Chinese livestock and poultry resources, 2004. Chinese livestock and poultry resources. Chinese Agriculture Press, China.

van den Boom, D., Jurinke, C., McGinniss, M.J. and Berkenkamp, S., 2001. Microsatellites: perspectives and potentials of mass spectrometric Analysis. Exp. Rev. Mol. Diagn., 1: 383-393. https://doi.org/10.1586/14737159.1.4.383

Wahl, M.C., Will, C.L. and Lührmann, R., 2009. The spliceosome: design principles of a dynamic RNP machine. Cell, 136: 701-718. https:/doi. org/10.1016/j.cell.2009.02.009

Wang, X.Y., Yang, Q., Wang, K., Yan, H.L., Pan, C.Y., Chen, H., Liu, J.W., Zhu, H.J., Qu, L. and Lan, X.Y., 2019. Two strongly linked single nucleotide polymorphisms (Q320P and V397I) in GDF9 gene are associated with litter size in cashmere goats. Theriogenology, 125: 115-121. https://doi. org/10.1016/j.theriogenology.2018.10.013

Wang, K., Kang, Z., Jiang, E., Yan, H., Zhu, H., Liu, J., Qu, L., Lan, X. and Pan, C., 2020a. Genetic effects of DSCAML1 identified in genome-wide association study revealing strong associations with litter size and semen quality in goat (Capra hircus). Theriogenology, 146: 20-25. https://doi. org/10.1016/j.theriogenology.2020.01.079

Wang, Z., Zhang, X., Jiang, E., Yan, H., Zhu, H., Chen, H., Liu, J., Qu, L., Pan, C. and Lan, X., 2020 b. InDels within caprine IGF2BP1 intron 2 and the 3'-untranslated regions are associated with goat growth traits. Anim. Genet., 51: 117-121. https:// doi.org/10.1111/age.12871

Wei, W.H., Duan, Y., Haley, C.S., Ren, J., de Koning, D.J. and Huang, L.S., 2011. High throughput analyses of epistasis for swine body dimensions 
and organ weights. Anim. Genet., 42: 15-21. https:// doi.org/10.1111/j.1365-2052.2010.02082.x

Werner, S., Brors, B., Eick, J., Marques, E., Pogenberg, V., Parret, A., Kemming, D., Wood, A.W., Edgren, H., Neubauer, H., Streichert, T., Riethdorf, S., Bedi, U., Baccelli, I., Jücker, M., Eils, R., Fehm, T., Trumpp, A., Johnsen, S.A., Klefström, J., Wilmanns, M., Müller, V., Pantel, K. and Wikman, H., 2015. Suppression of early hematogenous dissemination of human breast cancer cells to bone marrow by retinoic acid-induced 2. Cancer Discov., 5: 506-519. https://doi.org/10.1158/21598290.CD-14-1042

Wu, W.J., Liu, K.Q., Li, B.J., Dong, C., Zhang, Z.K., Li, P.H., Huang, R.H., Wei, W., Chen, J. and Liu, H.L., 2018. Identification of an (AC)n microsatellite in the Sixl gene promoter and its effect on production traits in Pietrain $\times$ Duroc $\times$ Landrace $\times$ Yorkshire pigs. J. Anim. Sci., 96: 17-26. https://doi. org/10.1093/jas/skx024

Xin, W.S., Zhang, F., Yan, G.R., Xu, W.W., Xiao, S.J., Zhang, Z.Y. and Huang, L.S., 2018. A whole genome sequence association study for puberty in a large Duroc $\times$ Erhualian F2 population. Anim. Genet., 49: 29-35. https://doi.org/10.1111/ age. 12623

Yan, W., Wu, K., Herman, J.G., Xu, X., Yang, Y., Dai, G. and Guo, M., 2018. Retinoic acid-induced 2 (RAI2) is a novel tumor suppressor and promoter region methylation of RAI2 is a poor prognostic marker in colorectal cancer. Clin. Epigenetics, 10: 69. https://doi.org/10.1186/s13148-018-0501-4

Yang, J., Huang, L., Yang, M., Fan, Y., Li, L., Fang, S., Deng, W., Cui, L., Zhang, Z., Ai, H., Wu, Z., Gao, J. and Ren, J., 2016. Possible introgression of the VRTN mutation increasing vertebral number carcass length and teat number from Chinese pigs into European pigs. Sci. Rep., 6: 19240. https://doi. org/10.1038/srep 19240

Yuan, L., Zhai, L., Qian, L., Huang., Ding, Y., Xiang,
H., Liu, X., Thompson, J.W., Liu, J., He, Y.H., Chen, X.Q., Hu, J., Kong, Q.P., Tan, M. and Wang, X.F., 2018. Switching off IMMP2L signaling drives senescence via simultaneous metabolic alteration and blockage of cell death. Cell Res., 28: 625-643. https://doi.org/10.1038/s41422-018-0043-5

Zhang, J., Xiong, Y., Zuo, B., Lei, M., Jiang, S., Li, F., Zheng, R., Li, J. and Xu, D., 2007. Detection of quantitative trait loci associated with several internal organ traits and teat number trait in a pig population. J. Genet. Genom., 34: 307-314. https:// doi.org/10.1016/S1673-8527(07)60032-0

Zhang, L., Liang, J., Luo, W., Liu, X., Yan, H., Zhao, K., Shi, H., Zhang, Y., Wang, L. and Wang, L., 2014. Genome-wide scan reveals LEMD3 and WIF1 on SSC5 as the candidates for porcine ear size. PLoS One, 9: e102085. https://doi.org/10.1371/journal. pone. 0102085

Zhang, J., Yang, B., Wen, X. and Sun, G., 2018. Genetic variation and relationships in the mitochondrial DNA D-loop region of Qinghai indigenous and commercial pig breeds. Cell Mol. Biol. Lett., 23: 31. https://doi.org/10.1186/s11658-018-0097-x

Zhang, Y., Wang, K., Liu, J., Zhu, H., Qu, L., Chen, H., Lan, X., Pan, C. and Song, X., 2019. An 11bp indel polymorphism within the CSN1S1 gene is associated with milk performance and body measurement traits in Chinese goats. Animals (Basel), 9(pii): E1114. https://doi.org/10.3390/ ani9121114

Zhou, L.S., Zhao, W.M., Tu, F., Wu, Y.H., Ren, S.W. and Fang, X.M., 2019a. Physiology and genetics research progress of teat traits in pigs. Yi Chuan, 41: 384-390. [Article in Chinese]

Zhou, L., Zhao, W., Fu, Y., Fang, X., Ren, S. and Ren, J., 2019b. Genome-wide detection of genetic loci and candidate genes for teat number and body conformation traits at birth in Chinese Sushan pigs. Anim. Genet., 50: 753-756. https://doi.org/10.1111/ age. 12844 